\title{
Comparison of Injection Sclerotherapy Between 5\% Phenol in Almond Oil and Aluminum Potassium Sulfate and Tannic Acid for Grade 3 Hemorrhoids
}

\author{
Takaaki Yano, Kenji Yano \\ Yano Clinic of Proctology, Takamatsu, Japan
}

Purpose: Injection sclerotherapy for hemorrhoids has been performed for many years. Currently, 5\% phenol in almond oil (PAO) and aluminum potassium sulfate and tannic acid (ALTA) are used as the agents. The purpose of this study was to compare the efficacy of the two agents.

Methods: A retrospective study was conducted involving 135 patients who underwent injection therapy for grade 3 hemorrhoids for the first time between 2013 and 2014 (PAO, 55 patients; ALTA, 80 patients). The efficacy was established as the proportion (\%) of patients without symptoms such as hemorrhage and prolapse one year after treatment. We investigated four factors-sex, age, number of hemorrhoids, and agent-that might have an influence on the efficacy.

Results: The efficacies of ALTA and PAO one year after treatment were $75 \%$ and $20 \%$, respectively. Only the agent was a significant independent factor $(\mathrm{P}<0.01)$.

Conclusion: The results suggest that ALTA is markedly more useful than PAO for injection sclerotherapy for grade 3 hemorrhoids.

Keywords: Hemorrhoids; Injections; Sclerotherapy; Hemorrhage; Prolapse

\section{INTRODUCTION}

For injection therapy for hemorrhoids, two agents are primarily used. A well-established agent, 5\% phenol in almond oil (PAO), has commonly been used in the world for several decades $[1,2]$. A newer agent, aluminum potassium sulfate and tannic acid (ALTA; Zion, Mitsubishi Pharma Corp., Osaka, Japan), has recently been introduced in Japan and Korea $[3,4]$. As to the efficacy of injection sclerotherapy (IS) for the treatment of grade 3 hemorrhoids, PAO was reported to be ineffective [1] whereas ALTA was reported to be very effective [3]. However, IS with ALTA has not yet been commonly applied in the world. The rea-

Received: May 19, 2015 - Accepted: June 16, 2015

Correspondence to: Takaaki Yano, M.D.

Yano Clinic of Proctology, 11-7 Kamei-cho, Takamatsu, Kagawa 760-0050, Japan

Tel: +81-87-861-1515, Fax: +81-87-861-1516

E-mail: yanotakaaki@hotmail.co.jp

(c) 2015 The Korean Society of Coloproctology

This is an open-access article distributed under the terms of the Creative Commons Attribution NonCommercial License (http://creativecommons.org/licenses/by-nc/3.0) which permits unrestricted non-

commercial use, distribution, and reproduction in any medium, provided the original work is properly cited. son, in our opinion, is that no study has compared the two agents; thus, confidence in ALTA therapy is lacking. Therefore, many proctologists may hesitate to select ALTA therapy. In this study, we compared the efficacies of the two agents for treating grade 3 hemorrhoids.

\section{METHODS}

A retrospective observational study was conducted in 135 of the 149 patients who underwent injection therapy with PAO or ALTA for the treatment of grade 3 hemorrhoids for the first time in Yano Clinic of Proctology between April 2013 and March 2014. Sixteen patients were excluded because we could not get in touch with them (PAO, five patients; ALTA, 11 patients), and one patients with an anal fissure was excluded (ALTA, one patient). The subjects consisted of 55 treated with PAO and 80 treated with ALTA. The efficacy after one year was established as the primary endpoint. We compared the efficacies between the two agents.

\section{Treatment}

The subjects were placed in the Sims position, and an anoscope was inserted. An injection needle was inserted into the submuco- 
sal hemorrhoid tissue to infuse the solution with the agent (PAO or ALTA). For injection therapy, one physician was in charge of a single agent. The physician responsible for PAO therapy provided it for patients who visited our clinic on Wednesday or Thursday. The physician responsible for ALTA therapy provided it for those who visited our clinic on Monday, Tuesday, or Friday. The two physicians received the same training program for IS.

\section{Evaluation and definitions}

Prior to treatment, inquiries into two symptoms, hemorrhage and prolapse, was conducted by the physicians, and responses were recorded. At this point, hemorrhage was classified into three grades (Table 1) and prolapse into four grades (grade 1, no prolapse; grade 2, prolapse with spontaneous reduction; grade 3, prolapse with manual reduction; and grade 4, irreducible prolapse). One year after injection therapy for treating the hemorrhoids, the same inquiry was conducted by telephone. The treatment response was then evaluated. Only patients with "no hemorrhage" and "no prolapse" one year after treatment were regarded as responders. The other patients were regarded as nonresponders. Furthermore, patients who received additional treatment for hemorrhoids within one year after injection therapy were regarded as nonresponders. The efficacy rate (\%) was calculated by using the following formula: number of responders/(number of responders + nonresponders $) \times 100$.

Table 1. Comparison between PAO and ALTA for the treatment of hemorrhoids

\begin{tabular}{lccc}
\hline Variable & PA0 $(\mathrm{n}=55)$ & ALTA $(\mathrm{n}=80)$ & P-value \\
\hline Sex & & & 0.31 \\
$\quad$ Male & 31 & 52 & \\
$\quad$ Female & 24 & 28 & \\
Age (yr), mean \pm SD & $57.9 \pm 15.1$ & $56.0 \pm 16.7$ & 0.52 \\
No. of hemorrhoids treated & & & 0.61 \\
1 & 13 & 28 & \\
2 & 29 & 29 & \\
3 & 13 & 23 & 0.83 \\
Hemorrhage & & & \\
None & 20 & 31 & \\
Bleeding on paper & 19 & 21 & $<0.01$ \\
Blood dripping in toilet & 26 & 28 & \\
Treatment responses & & & \\
Responders & 11 & 60 & \\
Nonresponders & 44 & 20 & \\
Efficacy rate (\%) & 20 & 75 & \\
\hline PAO $5 \%$ pheno & & & \\
\hline
\end{tabular}

PAO, 5\% phenol in almond oil; ALTA, aluminum potassium sulfate and tannic acid; $\mathrm{SD}$, standard deviation.

\section{Statistical analysis}

To identify the factors affecting the efficacy, we conducted univariate analyses for the following four parameters for comparison between the responder and the nonresponder groups: sex, age, number of treated hemorrhoids, and agent (ALTA/PAO). Continuous and ordinal variables were analyzed by using the MannWhitney U-test, and categorical variables were analyzed by using the chi-square test. The four parameters were forcibly included in the logistic multivariate analysis. The odds ratios are reported with $95 \%$ confidence intervals. All of the statistical analyses were performed using the SPSS ver. 12 (SPSS Japan Inc., Tokyo, Japan). For all comparisons, a value of $\mathrm{P}<0.05$ was considered to indicate a statistically significant difference.

\section{RESULTS}

The characteristics of the 135 patients are presented in Table 1 . The efficacy rates of ALTA and PAO were $75 \%$ and $20 \%$, respectively, showing a significant difference $(\mathrm{P}<0.01)$. The results of the univariate analysis using four variables (sex, age, number of treated hemorrhoids, and agent [ALTA/PAO]) for the efficacy are shown in Table 2. Those of the multivariate analysis using the four

Table 2. Univariate variables of efficacy

\begin{tabular}{lccc}
\hline Variable & $\begin{array}{c}\text { Responders } \\
(\mathrm{n}=71)\end{array}$ & $\begin{array}{c}\text { Nonresponders } \\
(\mathrm{n}=64)\end{array}$ & P-value \\
\hline Sex & & & 0.24 \\
$\quad$ Male & 47 & 36 & \\
$\quad$ Female & 24 & 28 & \\
Age (yr), mean \pm SD & $56.6 \pm 17.1$ & $56.9 \pm 14.9$ & 0.95 \\
No. of hemorrhoids treated & & & \\
1 & 26 & 15 & 0.42 \\
2 & 25 & 33 & \\
3 & 20 & 16 & \\
Agent used & & & $<0.01$ \\
PA0 & 11 & 44 & \\
ALTA & 60 & 20 & \\
\hline
\end{tabular}

SD, standard deviation; PAO, 5\% phenol in almond oil; ALTA, aluminum potassium sulfate and tannic acid.

Table 3. Multivariate variables of efficacy

\begin{tabular}{lccc}
\hline Variable & Odds ratio & $95 \% \mathrm{Cl}$ & P-value \\
\hline Sex (male/female) & 1.41 & $0.61-3.27$ & 0.43 \\
Age & 1.01 & $0.98-1.03$ & 0.73 \\
No. of hemorrhoids treated & 0.87 & $0.51-1.50$ & 0.61 \\
Agent used (ALTA /PA0) & 11.9 & $5.15-27.6$ & $<0.01$ \\
\hline
\end{tabular}

$\mathrm{Cl}$, confidence interval; ALTA, aluminum potassium sulfate and tannic acid; PAO $5 \%$ phenol in almond oil. 
variables for the efficacy are presented in Table 3. Only the agent (ALTA/PAO) was an independent significant factor influencing the efficacy $(\mathrm{P}<0.01)$.

\section{DISCUSSION}

The results of IS with PAO for the treatment of grade 3 hemorrhoids are unfavorable [1]. A poor impression of IS has, for many years, caused proctologists to hesitate to select it. The current study showed that ALTA therapy was markedly more useful than PAO therapy. This may change the unfavorable impression of IS. Although surgery alone has been recommended as a treatment option [5], ALTA injection therapy may become a new treatment option.

In this study, the efficacy rates of ALTA and PAO after 1 year were $75 \%$ and $20 \%$, respectively. When these values were compared with those in a previous study $(84 \%$ and $20 \%$, respectively $[1,3])$, there were no marked differences. However, this is the first study comparing the two agents. A marked difference was observed in the efficacies of two agents, possibly because the sclerosing/hemostatic actions of ALTA were more potent than those of PAO. Thus, the application of PAO for the treatment grade 3 hemorrhoids should be avoided.

This study has some limitations: It was a retrospective, nonrandomized study, and it was only based on inquiries. Only with a prospective, randomized, controlled, multicenter study involving a practical anal examination can these limitations be finally removed. In conclusion, this study suggests that ALTA is markedly more useful than PAO for IS for the treatment of grade 3 hemorrhoids. We should select ALTA, not PAO, as the agent for treating grade 3 hemorrhoids.

\section{CONFLICT OF INTEREST}

No potential conflict of interest relevant to this article was reported.

\section{REFERENCES}

1. Greca F, Hares MM, Nevah E, Alexander-Williams J, Keighley MR. A randomized trial to compare rubber band ligation with phenol injection for treatment of haemorrhoids. Br J Surg 1981; 68:250-2.

2. Khoury GA, Lake SP, Lewis MC, Lewis AA. A randomized trial to compare single with multiple phenol injection treatment for haemorrhoids. Br J Surg 1985;72:741-2.

3. Takano M, Iwadare J, Ohba H, Takamura H, Masuda Y, Matsuo K, et al. Sclerosing therapy of internal hemorrhoids with a novel sclerosing agent: comparison with ligation and excision. Int J Colorectal Dis 2006;21:44-51.

4. Lim SW. Aluminum potassium sulfate and tannic acid injection for hemorrhoids. J Korean Soc Coloproctol 2012;28:73-7.

5. Cataldo P, Ellis CN, Gregorcyk S, Hyman N, Buie WD, Church J, et al. Practice parameters for the management of hemorrhoids (revised). Dis Colon Rectum 2005;48:189-94. 